\title{
Microstructural Analysis of 3D-Printed Alloy 718.
}

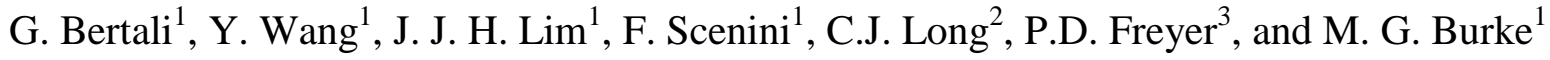 \\ ${ }^{1 .}$ Material Performance Centre, The University of Manchester, Manchester (UK) \\ ${ }^{2}$ Westinghouse Electric Company LLC, Hopkins, SC 29061 (USA) \\ ${ }^{3}$ Westinghouse Electric Company LLC, Pittsburgh, PA 15235 (USA)
}

Three-dimensional printing (3DP), as an emerging additive manufacturing process in the last decade, is a promising technique for high-speed low-cost fabrication of complex parts compared with traditional methods. Although it is possible to 3D print complex alloys such as Ni-Cr-Fe alloys and stainless steels, the effect of this manufacturing process on the material microstructure remains a topic of research.

The microstructural complexity of Ni-Cr-Fe-Nb-Ti-Al alloy (Alloy 718) especially in terms of second phase precipitation is well-known and has been extensively characterized and studied in the past [1-3]. The main precipitates that have been identified in Alloy 718 are $\gamma^{\prime \prime}\left(\mathrm{Ni}_{3}(\mathrm{Nb}, \mathrm{Ti})\right), \delta\left(\mathrm{Ni}_{3} \mathrm{Nb}\right), \gamma$ ' $\left(\mathrm{Ni}_{3}(\mathrm{Al}, \mathrm{Ti})\right), \mathrm{MC}, \mathrm{M}_{23} \mathrm{C}_{6}, \mathrm{M}_{7} \mathrm{C}_{3}, \mathrm{M}_{6} \mathrm{C}$ and Laves. 3D-printed Alloy 718 microstructure is expected to be characterized by the presence of the same precipitates. However, the extent and distributions of these precipitates might be different from the conventionally-produced wrought alloy. These possible microstructural variations may affect macroscopic properties of the alloy such as elevated temperature resistance, creep resistance and strength. Therefore, a detailed microstructural characterization of the 3D printed Alloy 718 is needed in order to assess any differences from the conventionally-produced alloy.

In this study, a combination of field-emission gun (FEG) scanning electron microscopy (SEM), brightfield (BF) and dark-field (DF) transmission electron microscopy (TEM), and analytical electron microscopy (AEM) techniques have been used to study the microstructure developed in 3D-printed Alloy 718 with emphasis on the type and extent of precipitation.

The as-polished Alloy 718 was examined in a Zeiss MERLIN FEG-SEM with a GEMINI II column using both secondary electron (SE) and backscattered electron (BSE) modes. The microstructure was characterized by a layered and elongated grain structure (Fig. 1(a)) and by numerous subgrains (Fig. 1(b)). High resolution energy-selected backscattered electron analysis highlighted three different precipitate morphologies: coarse globular and plate-like intergranular brightly-imaging precipitates and fine acicular intragranular brightly-imaging precipitates. TEM analysis confirmed that the intragranular precipitates were $\gamma$ " with a size of $\sim 100 \mathrm{~nm}$ (Fig. 2). Discrete needle-like $\delta$ precipitates preferentially precipitated at high-angle grain boundaries. High resolution scanning transmission electron microscope (STEM) energy dispersive X-ray (EDX) microanalysis, using the FEI Titan G2 80-200 aberration corrected S/TEM equipped with super EDX, revealed marked micro-chemical variations in the fine precipitates. The disc-shaped $\gamma$ " was composed of $\mathrm{Ni}, \mathrm{Nb}$ and $\mathrm{Ti}$, with a small amount of $\mathrm{Al}$, and served as a nucleation site for subsequent precipitation of very fine $\gamma$ " precipitates, which were enriched in Al (Fig. 4). These results will be discussed and compared with conventionally thermally-treated Alloy 718.

\section{References:}

[1] M.G. Burke et al. J. de Physique (1989) p. C8 395-400.

[2] Moukrane Dehmas et al. in Advances in Materials Science and Engineering (2011).

[3] D.F. Paulonis et al. in Trans. ASM (1969) p. 611. 

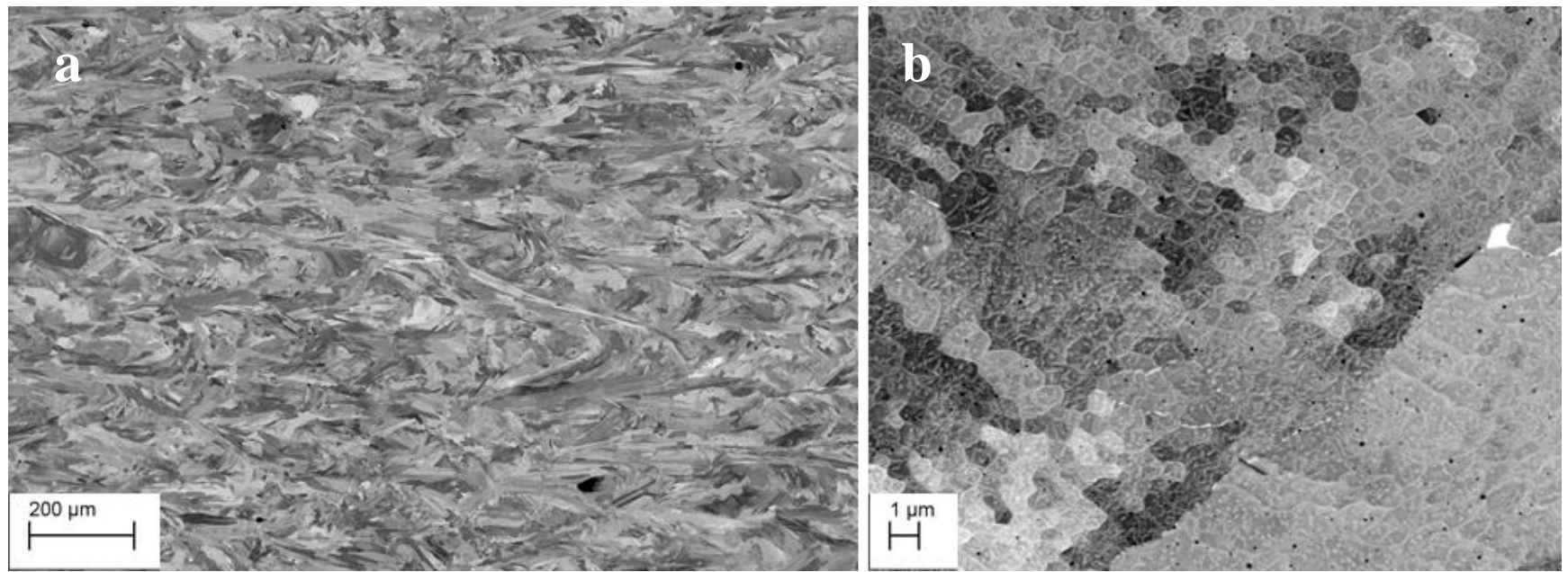

Fig. 1: $(a, b)$ BSE images of the 3D-printed Alloy 718 microstructure and the subgrain structure.

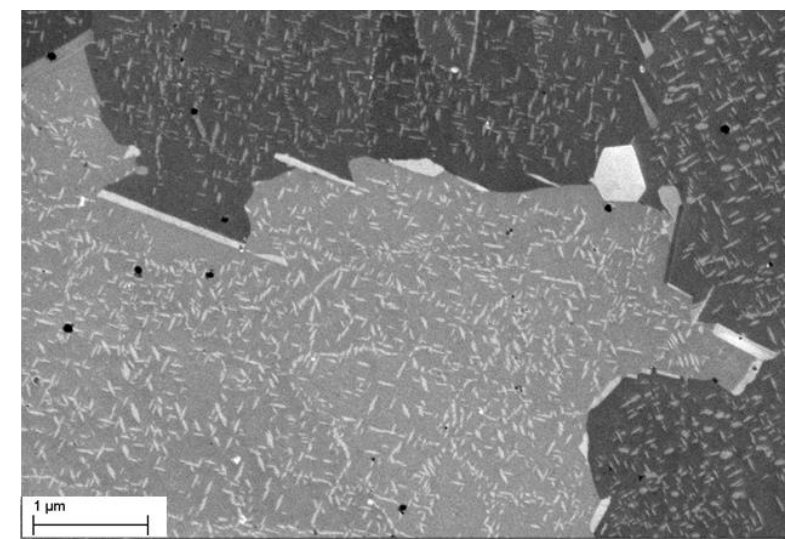

Fig. 2: BSE image showing the brightly-imaging precipitates $(\gamma$ " and $\delta)$ with different morphologies.

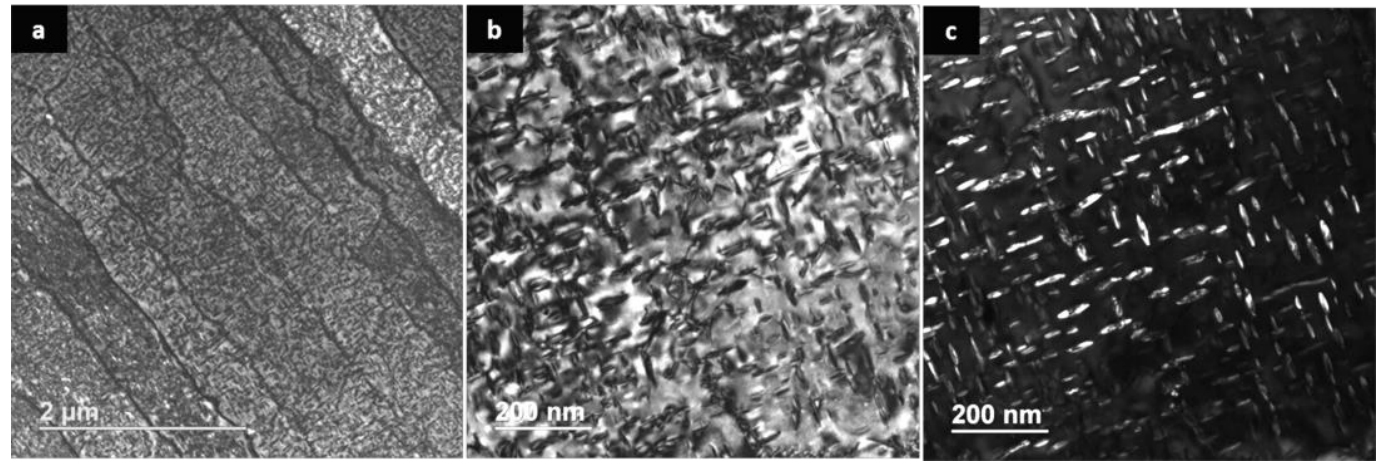

Fig. 3: TEM images of (a) the subgrain structure; (b) [001] BF and (c) DF images of the intragranular $\gamma$ ".

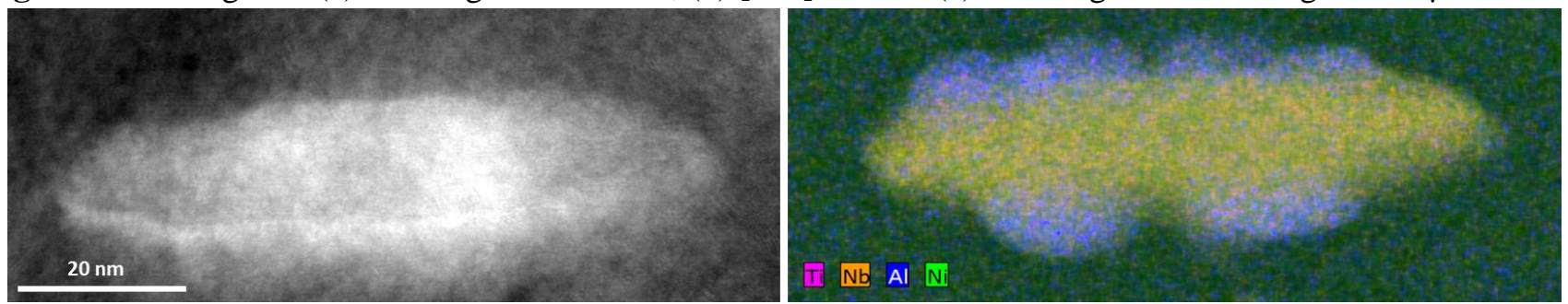

Fig. 4: HAADF STEM image and corresponding Titan "ChemiSTEM" SDD EDX spectrum images for Ti, Nb, $\mathrm{Al}, \mathrm{Ni}$ of a coarse $\gamma$ " precipitate with smaller discrete $\gamma$ ' precipitates that have nucleated at the $\gamma$ "/matrix interface. 